\title{
Networks of Contention: The Shape of Online Transnationalism in Early Twenty-First Century Social Movement Coalitions
}

Stefania Vicari (Sv32@1e.ac.uk)

Department of Media and Communication, University of Leicester

Abstract. The study of new media use by transnational social movements is central to contemporary investigations of social contention. In order to shed light on the terrain in which the most recent examples of online mobilization have grown and developed, this paper combines the interest in the transnational dynamics of social contention and the exploration of the use of new ICTs for protest action. In specific terms, the study investigates how early twenty-first century social movement coalitions used Internet tools to build symbolically transnational collective identities. By applying a Hyperlink Network Analysis approach, the study focuses on a website network generated by local chapters of the World Social Forum, one of the earliest social movement coalitions for global justice. The sample network, selected through snowball sampling, is composed of 222 social forum websites from around the world. The study specifically looks at hyperlinks among social forum websites as signs of belonging and potential means of alliance. The analysis uses network measures, namely of cohesion, centrality, structural equivalence, and homophily, to test dynamics of symbolic collective identification underlying the WSF coalition. The findings show that in early twenty-first century transnational contention culture and place still played a central role in the emergence of transnational movement networks.

\section{Introduction}

The recent "Occupy" and "Indignados" mobilizations in many Western countries have attracted renewed scholarly attention on the use of ICTs in processes of social contention. In fact, questions on the role and power of new media in transnational waves of social contention have emerged stronger than ever before. However, the integration of new 
information and communication technologies in protest action has affected the development of social movements and social movement coalitions already since the end of the twentieth century.

Social movement and media and communication studies interested in contemporary contention range from analyses of movement organization and structures (Andretta at al. 2002: 34-72; Reiter, et al. 2007: 56-73), to studies on the internationalization of dissent (della Porta et al. 2009; Routledge and Cumbers 2009; Smith et al. 2002; Tarrow 2005a, 2005b), on to theorizations of protest identities (Andretta et al. 2002: 73-106; della Porta 2006; Reiter et al. 2007: 63-72), and the use of new media in general (Bennet 2003; della Porta and Mosca 2005; Langman 2005; Mosca and della Porta 2009; Cottle and Lester 2011) and social media in particular (Bajpai and Jaiswal 2011; Bennet and Segerberg 2011; Christensen 2011; Procter et al. 2011; Rahimi 2011; Segerberg and Bennet: 2011).

In order to shed light on the terrain in which the most recent examples of online transnational mobilisation have grown and developed, this paper combines the interest in the transnational dynamics of social contention and the exploration of the use of ICTs by early twenty-first century social movement coalitions. By applying a Hyperlink Network Analysis (HNA) approach, the aim is that of mapping the online symbolic construction of transnational social movement identities. The study specifically focuses on the World Social Forum (WSF) coalition by looking at the early website network produced by its local chapters, i.e., local social forums from around the world.

In the following sections, the paper will discuss theoretical contributions on the use of ICTs by transnational movement coalitions. Next, data and methods will be described. The remainder of the paper will specifically develop four lines of investigation: a cohesion analysis of the WSF website network, the identification of its central nodes, the mapping of its internal subnetworks, and the measurement of its overall networking patterns. 


\section{Early Twenty-First Century Transnational Protest and the New Media Ecosystem}

\subsection{Local, National, and Transnational}

One of the most relevant features of contemporary social movements since the end of the twentieth century has been the new level of transnationalism, or the cross-national diffusion of protest ideas and actions. Transnationalism has characterised social action since the development of the nation-state (Keck and Sikkink 1998), when diffusion and mobilization from above were the mechanisms through which it operated (Tarrow 2005a: 3). Diffusion and international mobilization have generated modularity, or the adaptation and reformulation of similar protest practices in different places.

However, two processes have marked the shift from traditional to new forms of transnationalism: the contemporary globalization wave and the structural changes of international politics (Tarrow 2005a: 5). According to Tarrow, the first factor has provided incentives and purposes for social contention (2005a: 99-119). In fact, since the end of the twentieth century, activist movements have become ever more likely to mobilise in local, regional and national protests focused on globalization issues. Some of their labels, to only name the most commonly referred to, became: antiglobalization, global justice, global civil society (Bennet 2003; Koopmans 2004). As Tilly points out: "the international construction of "we" became an increasingly familiar feature of twenty-first century social movements" (Tilly 2004: 114). A sense of common belonging, paralleled by the need for shared repertoires of action, permeated protest performances enhancing transnational dynamics.

The second process marking the shift toward contemporary transnationalism was brought about by the structural changes in the context of international politics. In fact, such changes have provided the targets of protest within the new interpretative schemata for collective action. In particular, the creation of international authorities such as the United Nations, the North Atlantic Treaty Organization, and the European Union at the regional 
level, and the World Trade Organization, the International Monetary Fund, the World Bank, and the G8 at the global level, led to the emergence of consequential counter-actors in the public sphere (Wood 2004). The multiplication of multilateral connections among activist groups mobilizing against these transnational institutions, and more generally against neoliberal policies, generated different levels of interaction at local, national, and international level, shifting their target towards shared and more general objects of claim. Towards the end of the twentieth century, internationally coordinated social movement performances and international backing for regional and national social movement events started taking place more frequently than ever before (della Porta and Tarrow: 2005).

In sum, transnational processes emerging in early twenty-first century social contention concerned different dimensions: international relations between state and non-state actors, vertical relations between different territorial levels (i.e., local, national, and international), and the reticular relation among different social actors. As Tarrow points out, internationalism "today is complex, horizontal, and vertical" (2005a: 9). In the last edition of Power in Movement. Social Movement and Contentious Politics (2011), Tarrow suggests a new interpretation of contemporary transnationalism, highlighting how the 1999 anti-WTO protest in Seattle was the turning point in the history of transnational activism. He summarises the four processes characterising contemporary transnationalism:

1) Localisation, or the use of local tactics to protest against national authorities in defence of civil rights threatened by external causes;

2) Global framing, or the reinterpretation of local issues in transnational contexts;

3) Externalisation, or the mobilization of local actors against transnational issues;

4) Emergence of transnational coalitions, or the origin of transnational networks of protest (2011: 234-258). 
Now, given the shift from traditional modular internationalism to contemporary transnationalism, how have new ICTs participated in the development of early twenty-first century transnational social movement coalitions?

\subsection{ICTs and Network Structures}

Since the end of the twentieth century newly available media have progressively entered the sphere of social contention, contributing to the evolution of contemporary advocacy actors. Recent literature has highlighted how early digital communication participated in the change of protest actors by favouring the emergence of loosely structured networks as opposed to the dense coalitions of earlier social movements (Bennett 2003; Mosca and della Porta 2009: 195).

According to Bennett, early digital communication practices had a series of specific effects on global activism: "These effects range from organizational dynamics and patterns of change, to strategic political relations between activists, opponents and spectator publics. In addition, patterns of individual participation appear to be affected by hyperlinked communication networks that enable individuals to find multiple points of entry into varieties of political action.” (2003: 144). Drawing upon Bennett (2003), Castells identifies three specific dimensions of Internet-based networking: "strategic, organizational, and normative." (2011: 343). First, Internet use by social movement activists eased the diffusion of counterinformation on alternative media networks. For instance, among advocacy actors engaged in protests for global justice, Indymedia - a network of activist media centres - became a key instrument to provide direct protest coverage. Hence, Internet use eased processes of "disintermediation": "movements present themselves directly to the general public with low costs especially facilitating resource-poor actors" (della Porta and Mosca 2005: 166). Second, movements often evolved into projects "of societal organisation around networked selfmanagement" (Castells 2011: 345) with more or less temporary merges of different advocacy 
actors. In fact, in an era in which transnational networks emerge from the aggregation of different organisations and advocacy actors concerned with globalisation issues, the role of new media becomes of paramount importance. The WSF itself connected together local struggles from around the world under the umbrella claim "Another world is possible" (forumsocialmundial.org.br). Third, universal calls for justice started entering the international agenda of mainstream media, stimulating new normative discussions. As Giugni (2012) highlights, the protests for global justice mushroomed in the early twenty-first century did not directly impact the political sphere, they rather contributed to the diffusion of public discussions of issues related to global justice. We are here addressing a cultural rather than political effect "to the extent that some of the movement's demands, once they have entered the public domain, gain legitimacy and may change the way institutional actors frame a given issue" (Giugni 2012).

In sum, new ICTs have provided early twenty-first century social movement coalitions with new resources for mobilisation, political opportunities and platforms for framing purposes, facilitating transnational mobilisation, diffused strategies, and polycentric protest events. But how and to what extent did the use of new ICTs ease the symbolic construction of transnational collective identities? Which patterns characterised these forms of digital use in the representation of global dissent? The study will specifically address these questions by investigating the early WSF website network.

\section{Data and Methods}

\subsection{Case Study: The World Social Forum}

By employing an exploratory approach, this paper aims to map online transnational dynamics typical of twenty-first century social movement coalitions. The attention is drawn to the WSF, a transnational coalition of protest groups engaged in local and transnational 
mobilisations for global justice. With its emphasis on participation and the power of its communication channels, the WSF has grown as a global social space where diverse organizations network united by the common goal of opposition to neo-liberal political and economic policies. It represents the gathering of multifaceted, heterogeneous movements that incorporate many social, generational and ideological groups as well as movement organizations from different countries (della Porta 2005: 73).

The first WSF yearly event, conceived as a counter-event to the World Economic Forum (WEF), was held in Porto Alegre, Brazil, in 2001. The delegates' registration and the organization of the meetings were run online; thematic bulletin boards informed the delegates via email and basically all the internal communication and the external relations developed on the Internet (Schonleitner 2003: 130). Since 2001, the WSF has become both a yearly event and a stable online social space for local groups committed to the mobilisation for global justice. In fact, the idea and open structure of the WSF ha been replicated and adapted to decentralized realities, in the construction of local civic networks which interact primarily over the Internet. In 2004 the WSF yearly event was held in Mumbai with the aim to bolster the transnationalisation of the WSF diffuse network. Since 2005 several WSF early meetings have turned into polycentric events. In the meantime, thousands of WSF-related decentralised events have been mobilised all around the world.

\subsection{Methodological Approach}

In order to map transnational dynamics of collective identification in WSF local chapters, this study explores a sample of social forum websites by applying a HNA approach. HNA focuses on the contextual environment generated by website networks - network of websites connected among themselves - rather than on single websites. As Park and Thelwall state: "Given this interweaving hyperlinking structure, it may be necessary to recognize individual websites as mutually dependent entities, which constitute a web system." (2003: online). 
Jackson adds: "the utility of network analysis is not the production of a map, it is the ability to assess and represent the nature of communication structure. This is precisely the methodological problem that needs to be addressed in the study of Web-based communication" (Jackson 1997: online). In other words, not only HNA can uncover factors affecting a website network's overall cohesion, it also helps to investigate online dynamics of self-representation and identification with others.

With the aim of drawing a sample network representative at the geographical level, two social forum websites of different nationality were retrieved per each continental area (Africa, South America, North America, Asia, Europe, and Oceania). Given the presence of websites representative of both city and national forums, where possible, one website per type was selected ${ }^{\mathrm{i}}$. Furthermore, for Europe, Asia and Africa, one website edited in characters different from Latin was selected (Greek, Iranian and Moroccan websites). Table 1 lists the initial 12 websites.

[Table 1 about here]

The overall sample network was then designed by using a snowballing technique: starting from the initial 12 websites, all the links from one social forum website to another were tracked and coded. As a result, this study is focused on a 222-node sample network with no isolated unit: each website under investigation was in-linked by at least another website. ${ }^{\text {ii }}$ The HNA of the sample network was conducted via the use of UCINET Software for social network analysis.

\section{Online Transnational Dynamics in the early WSF Website Network}

\subsection{Network}

Through its modular diffusion, the WSF anti-neoliberal manifesto has been normalized and redelivered in multiple ways at the local level. Different political, cultural and social factors seem to have affected the WSF's early development process across the world. The analysis 
of online dynamics of symbolic interaction will help interpret the initial transnational processes characterising the WSF network.

HNA allows one to understand who is connected to whom online and to test whether the online environment reproduces socio-geographic characteristics of the offline sphere or may potentially open up new supranational alliances. The first central indicator provided by HNA is the overall level of network cohesion, measured on the basis of the density of links among the nodes. Calling $\mathrm{N}$ the sample size and $\mathrm{M}$ the number of links, the density of directed links is measured as $\mathrm{M} /[\mathrm{N}(\mathrm{N}-1)]$ (Granovetter 1976: 1288). Network cohesion measures allow one to evaluate how integrated a network is. A low-cohesion value corresponds to a small number of links among the network nodes and a weak overall network interaction (Van Aelst and Walgrave 2004: 117). In the case of maximum cohesion, when all network nodes are interconnected, the density value will be 1 .

The actual density of this study's sample network equals 0.03 . In fact, the mean of 6 directional ties $^{\text {iii }}$ (i.e., outgoing links) per each single node, out of the potential 221, prevents us from speaking of a close-knit network. Reciprocal linking throughout a network of websites appears to be quite rare. As Van Aelst and Walgrave suggest in their study on a network of Anti-Globalization websites: "The practice of linking is clearly not always a reciprocal one, which means that not all relations are equally strong." (2004: 117) One reason for this is that websites may not be frequently updated once they are set up. This means that a new website will link to existing websites but they will not reciprocate. In fact, the WSF network seems to confirm this conclusion. The Austria Social Forum website was, for example, the most 'bonding' forum within the sample network, with its 68 outlinks towards other social forum websites, but it was itself linked to by only 16 others. Conversely, the Brazilian website of the WSF, which had 30 outgoing links, was in-linked by 74 social forum websites. 
[Figure 1 about here]

Figure 1 shows the visual representation of the sample network. Nodes stand for social forum websites while ties stand for hyperlinks, with their arrowheads indicating the direction of the hyperlinks. Different colours stand for different continental areas. Figure 1 shows two central characteristics of the WSF website networks: the high participation levels of European forums and the shaping of different geographical blocks emerging in different areas of the network. North and South American nodes, in particular, hold quite close-knit locations within the network's map. Let's then focus on the network's individual nodes and on their relational patterns.

\subsection{Central Nodes}

In network environments, a node's power is defined by its centrality within the network and is measured in terms of relational strength. Number and type of ties are central to a node's power. One of the important outcomes of HNA is, in fact, the identification of central nodes, in this case central websites, usually playing the role of hubs, brokers, and authoritative or prestigious actors.

In order to find the network's central nodes and display their specific features within the network, we can use two different centrality tests: Freeman and Betweenness. In the case of an asymmetric network, Freeman centrality is the measure of inlinks (indegree) and outlinks (outdegree) for each single node (Freeman 1979: 219-221). Betweenness centrality measures how often a node lies on the shortest path - geodesic - between other two nodes in the network ${ }^{\mathrm{iv}}$. Nodes with a high score in betweenness centrality usually play the role of hubs or brokers, being of vital importance for the connection between two other nodes.

[Table 2 about here]

Table 2 only reports network nodes with highest centrality measures. It is not surprising that the Brazilian site of the WSF had the highest number of incoming links (indegree) and most 
often connected in short path other two forums (betweenness). This would suggest that the core centre of network identification in 2005, when data was collected, was still highly rooted in its original nucleus. In fact, the Indian website of the WSF, only born in 2004, held a less central position. Nevertheless, the Brazilian website's outdegree value - measure of the number of outgoing links - was not high. This result leads to a layered interpretation. On the one side, data seem to strengthen theories that see early twenty-first century protest movements as characterized by loose structures (Tarrow 1998; Castells 2001), while on the other side they show the decentralized shape typical in the longitudinal development of international protest networks (Escobar 2004).

The same consideration can be applied to the European Social Forum which, in fact, had high indegree but low outdegree. Austrian and New York social forums worked as brokers with links to a high percentage of other forums. The first, in particular, was the only actor that, with the Brazilian WSF, worked as a bridge for many pairs of forums (betweenness). The remaining central nodes were all Italian social forums linking to a high percentage of other forums. This suggests that the Italian participation to the WSF process, beyond being numerically more relevant than that of other countries, showed special characteristics: Italian websites had more connections with other websites and tended not to lose contact with the network's central nodes. Yet, what centrality measures do not explain is the direction of the links sent or received by central nodes. In a specific area of the network there might be a relational bias that centrality indicators would not show. By showing which nodes work as brokers or connectors one can identify the network's centres of power. However, centrality measures do not describe microenvironment dynamics within the network. 


\subsection{Subnetworks}

A Test of Structural Equivalence displays whether specific relational patterns characterise different network subgroups. Investigating the presence of structural equivalences means identifying nodes with identical relations and therefore more likely to compete to obtain an influent position within the network. Therefore, "Structural equivalence overlaps, restricts and extends the concepts of cohesion" (Burt 1987: 1291). In other words, this test can tell whether certain nodes receive and send links from and to exactly the same nodes.

Figure 2 represents the WSF sample network by using a principal components layout. Instead of describing the network along a single dimension (e.g. degree centrality), the principal components layout decomposes the relationship matrix, by placing nodes near each other to the extent that they are structurally equivalent (Borgatti et al. 2002). While not the only method to measure structural equivalence, a principal components analysis allows for an effective visualization of the overall network in terms of broad structural equivalences. Figure 2 shows that the WSF network was clearly divided into four areas with most nodes sitting in two distinct groups on the left and the bottom centre of the figure, respectively. A third block is located in the bottom right area of the graph while the fourth block sits along the right top-down line of the graph. In this phase of the analysis we need to draw the attention to this fourth area. The graph clearly shows how WSF, European, Austrian and New York Social Forum, each either linking or being linked to by more nodes than any others, are to be distinguished from the rest of the network. They served as critical connectors, either fortifying the network identity or working as network brokers. Interestingly, the Indian WSF website sits in the cleavage between the WSF Brazilian website and the block with the highest number of network nodes, displaying its intermediate WSF identity power.

[Figure 2 about here] 
Given the low value of network cohesion and the network's structural heterogeneity, it is now interesting to analyze the presence of more specific internal subgroups. The actual involvement of individual nodes in the overall network or in a network's subgroup is a measure of "embeddedness" (Bach and Stark 2005). To display the presence of close-knit internal groups, we can look for specific structural equivalences within the network. A test of structural equivalence via cluster analysis allows us to show clusters of specific positions of the network's nodes, disclosing whether there are subgroups of network members marked by specific characteristics.

The cluster analysis shows that in the sample network the 222 initial structural positions decrease to 8 (Figure 3).

\section{[Table 3 about here] [Figure 3 about here]}

Four out of the eight blocks are mainly Italian (i.e., blocks 5, 6, 7 and 8), one is mainly German (i.e., block 1) and the other three blocks (i.e., 2, 3 and 4) group all the remaining forums. This means that a high number of nodes (block 3, around 30\% of the websites) had similar structural positions in the network and received links from all the other nodes apart from those belonging to blocks 7 and 8 (entirely Italian). The other two blocks with forums of different geographical connotation (i.e., blocks 2 and 4) were characterized by fewer incoming and outgoing links from/towards other blocks ${ }^{\mathrm{v}}$. The German block (1), represents a structural position with outgoing links towards blocks 2, 3, 5, and 6 and incoming links from all the other blocks but the Italian ones. The Italian blocks are of two types: 5 and 6 are integrated in the network and interact with 1, 4, and 3 while blocks 7 and 8 represent structural positions where the nodes only interact with other Italian forums (blocks 5 and 6). This means that a group of Italian forums was essentially isolated from the rest of the WSF network, only building up alliances with other national protest groups. 
These findings show that while through the Internet the internal communication of early twenty-first century movement coalitions could overcome national barriers (Andretta et al. 2002: 67), this probably mainly happened in relation to specific events, e.g., the mobilization of demonstrations or protest campaigns. The few permanent international channels seem to have rather worked as symbolic sources of identification with the overall transnational network, or a way for local groups to express their belonging to a transnational collective identity

\subsection{Overall Networking Patterns}

Relational tendencies can be affected by intrinsic and extrinsic factors: actors' attributes and environmental characteristics might ease or hamper a network's integration. As Hanneman and Riddle suggest: "The notion that similarity (or homophily) increases the probability of the formation of social ties is central to most sociological theories. The homophily hypothesis suggests that if two actors are similar in some way, it is more likely that there will be network ties between them" (2005: online). Hence, according to homophily theories, if we study a social network that contains different types of actors, the density of ties ought to be greater within each group than between groups. One can evaluate the extent of homophily and segregation by fitting one of the homophily models. These tests are analyses of variance in which there is a parameter estimated for each group interpretable as a measure of tendency toward "inbreeding" or homophily (Cross et al. 2001: 225). The least-specific notion of how members from different groups relate to one another is simply that the groups differ. Members of one group may prefer to have ties only within their group; members of another group might prefer to have ties only outside of their group.

Considering the diversity of the actors and the communication platform, we can focus on two central factors that might have structurally affected interaction dynamics: geographical proximity and language. In theory, the online environment eases global 
communication exchanges, shortening offline distances, timings, and costs. Yet, different studies have proved that geographical proximity plays a role in the level of global interaction over the Internet (Pudrovska and Ferree 2004; Stark et al. 2005; Van Aelst and Walgrave 2004: 118). At the same time, despite the horizontality of online channels, language issues could still hamper communications among actors.

The Variable Homophily Model is based on a categorical regression (Anova) applied to networks. It allows one to study the autocorrelation between the variable representing the network (actor-by-actor matrix) and the one representing the attribute (attribute-vector of each actor $)^{\mathrm{vi}}$. This model tests the hypothesis that actors prefer to interact with members of their own kind (as defined by an actor attribute), assuming that each group or class of actors has a different homophilic tendency (different inbreeding parameter).

[Table 4 about here]

[Table 5 about here]

In Table 4, the Variable Homophily Test indicates that language mattered: the relation is significant for all the most used languages but Catalan ${ }^{\text {vii }}$. Similarly, across continents there was a general tendency to relate to forums belonging to the same geographical area (see Table 5). Evidence is only missing for Africa and Asia.

In order to explore the network's overall interactions within and across continents, it was possible to run a Structural Block Model test. This test measures how within and between group ties differ across groups - but does not specify in what way they may differ (Hanneman and Riddle 2005: online). The test is based upon the link densities within each block and is similar to performing an analysis of variance (Borgatti et al. 2002).

[Table 6 about here]

[Figure 3 about here] 
The Structural Block Model Test is the most general autocorrelation test measuring the likelihood of interaction within and across groups (continental areas here). Table 6 shows the results of the test while Figure 3 maps the final findings. Basically, there is strong evidence that early local social forums from South America, North America, Oceania and Europe tended to have intra-continental links. The Blockmodel Test also shows that North American websites, beyond inbreeding, also had specific outbreeding tendency toward African and South American websites. This means that North American social forums knew their African and South American counterparts but were not reciprocated in the relational process. One might infer that North American forums all tended to stress their connection to the WSF movement by linking to its original South American websites. This specific outbreeding tendency might indicate the will to be recognized as part of a transnationally recognized movement. The North American outbreeding tendency toward African nodes might be the evidence of a specific attention toward third countries' forums.

Asian and African nodes did not show any relevant relational pattern. The early WSF diffusion process in these areas was far behind compared to the rest of the world. What we can infer from these results is that African and Asian forums were segregated both globally and locally.

\section{Discussion}

The structural connotation of the early WSF website network emerges as of a complex network where nodes and ties took specific features. By considering hyperlinks as the online basis for offline alliances, we can show how individual local social forum took part in the online identity formation of the WSF transnational process. As Garrido and Halavais point out: "Hyperlinks provide a direct measure of relationships among documents on the World Wide Web, and possibly an analogy for other structural relationships" (Garrido and Halavais 
2003: 167). In fact, the hyperlink has here two distinct meanings: it is a means of alliance and a sign of belonging.

The analysis of local social forums' interactions within the WSF website network is functional to the understanding of the transnational distribution of both power dynamics and representative potential. Social forum websites belonging to the WSF online network did not show high degrees of overall interaction and links were often not reciprocated. Yet, despite the lack of global integration and reciprocal connections, meaningful patterns developed at the micro level. The findings show that a few nodes were central along two specific lines of power: symbolic identification and brokerage. European and World Social Forum websites worked as symbolic master frames: referred to by a high percentage of forums, they worked as network connectors also for several segregated nodes (e.g. Judges Social Forum in Brazil, People World Water Social Forum in Switzerland). Where a local social forum built a special identity or dealt with specific themes, by reconnecting to the WSF website it could still attract attention and credibility from the rest of the network.

In the second possible power position, that of brokers, we find those few North American and European forums working as gatekeepers. These nodes sent and/or received a high number of links towards and/or from other network nodes, allowing exchanges between different subnetworks. In website networks, hyperlinking brokerage represents the existence of a path that a website reader might take from one website to another. Hence, the presence of broker websites increases the probability that users access those websites inliked by the website those users were originally visiting. If WSF and European forums symbolically glued the overall network, brokers like the Austrian Social Forum and the New York Social Forum physically tied it up by potentially expanding the WSF transnational network in the eye of the website viewer. A few Italian forums also emerged as central to the network's cohesion. 
The Italian fringe of the WSF online network was quite independent from the rest of the network. Both specific "expanding cultural opportunities" (McAdam 1994: 39) and opportunity structures might have influenced the WSF developing process in Italy. As Tarrow points out: "The international focus of transnational activism poses a paradox. On the one hand, international meetings, institutions and processes offer protesters a focal point for activism around which they can organize, meet others like themselves and form transnational networks. $[\ldots]$ On the other hand, the opportunity structures of the states to which they return to carry out their domestic activities have a powerful effect on the discourse and the practice of transnational activists." (Tarrow 2005: 60). Therefore, while the availability of transnational platforms of communication could have affected national levels of political opportunities (Ayres: 1999: 132), the shift of transnational civic engagement to the local level, or "downward scale shift" (Hadden and Tarrow 2007: 222), could have produced differences among national chapters. In fact, in the early transnational mobilization for global justice, while global targets gradually became local (downward scale shift), local claims started becoming global through processes of "upward scale shift" (Tarrow 2005: 120-140). In this context, Italian local social forum emerged from 2000 onwards provided a model to European activist groups that helped shape engagement at regional and transnational levels.

The analysis also showed that specific factors affected the way nodes linked to one another forming cohesive subnetworks. Inbreeding tendencies characterized all continental areas but Asia and Africa, meaning that social forums tended to interact with others of their own kind, in geographical terms. Linguistic and territorial belonging affected network integration: like in offline environments, exchanges were still more likely to occur within geographical borders. Only the North American fringe of the network showed some outbreeding patterns towards South American and African nodes. 
The lack of any type of relational pattern in both Asian and African chapters of the WSF network can be interpreted in relation to their low level of participation in the WSF online diffusion. It is relevant to recall that in 2005 the diffusion of the WSF process in Asia was at an early stage. The first Asian nodes went online in 2003 in relation to the temporary move of the WSF yearly encounter to Mumbai. The reason itself of the move was to involve and integrate Asian protest groups in the WSF process. In Leite's words: "The success of the Asian Social Forum [held in Hyderabad in 2003] significantly expanded the WSF process beyond the Latin American-Western European axis. It demonstrated that conditions existed in India to hold the fourth WSF as a world event of an importance equivalent to Porto Alegre. This would bring to the WSF process in its assemblage important elements of renewal and enrichment of the agenda, discourses and practices as well as provide potential for the expansion of the global movement in Asia" (Leite 2005: 130).

The first African social forum website went online in 2002, after the first African Social Forum took place in Mali in 2001. Yet, no relevant further diffusion occurred until 2004. This means that the WSF master frame in Africa was not replicated with success until that moment. The few existing African social forums were segregated from the network and not even cohesive among them. In fact, the African mobilization was mostly catalyzed after Mumbai 2004. The sixth World Social Forum meeting was a decentralized event taking place in three different locations: Mali, Venezuela, and Pakistan while the seventh World Social Forum was held in Nairobi, Kenya in January 2007. Gustave Messiah, one of the WSF delegates so describes the new African dimension: "we were afraid that the WSF might not go further than the polycentric Bamako Forum. As it turned out, our fears were unwarranted. The Forums (continental, national and local) strengthen one another and strengthen civil societies. At the Bamako Forum we witnessed the recognition and visibility of a structured African civil society [...]. At the Nairobi Forum, the African dimension was 
the most noticeable aspect, a meeting between the different Africas" (2007: online). Therefore, the WSF process started developing in the African continent much later than in the rest of the world.

\section{Conclusion}

Across early twenty-first century transnational protest coalitions, ICTs surely became a widespread resource for cross-border communication and exchange of old and new protest repertoires able to enhance new mechanisms of contention. Nevertheless, the analysis showed that online connectivity, at least in terms of online network cohesion, did not openly follow transnational routes. The WSF early online network was not dense and where cohesive subnetworks could be found, they shared language and/or territorial belonging. This shows that online interaction dynamics within protest coalitions were still highly based on cultural features that tended to recreate offline territorial borders. The strongest transnational ties from almost any network node outlinked the WSF node itself or a similar transnationally recognized member of the coalition.

The analysis uncovered two different online tie typologies: overall, links among social forum websites tended to connect nodes belonging to similar backgrounds and sharing cultural elements while transnational linkages held a rather symbolic value, bringing in credibility and authority for the node itself. In this sense, the network's structural analysis showed that the WSF's early coalition was not entirely transnational in terms of online interactions among local social forums. Its online developing process shows that the WSF's emergence bolstered interaction at local and national levels and enhanced transnational exchanges on a more symbolic dimension.

Hence, the study shows that it is at the local level that early twenty-first century transnational social movement coalitions like the WSF started achieving advocacy power. 
Transnationalism rather provided symbols for collective identification and cross-national solidarity via the modular diffusion of ideas and formats.

\section{References}

Andretta, M., Della Porta, D., Mosca, L. \& Reiter, H. (2002) Global, noglobal, new global. La protesta contro il G8 a Genova (Roma: Laterza).

Ayres, J. M. (1999) From the streets to the Internet: the cyber-diffusion of contention, Annals of the American Academy of Political Social Science, 566, pp. 132-43.

Bach, J. \& Stark, D. (2005) Recombinant Technology and New Geographies of Association. In: R. Latham and S. Sassen (Eds.) Digital Formations: IT and New Architectures in the Global Realm, pp. 37-53 (Princeton: Princeton University Press).

Bajpai, K. \& Jaiswal A. (2011) A Framework for Analyzing Collective Action Events on Twitter Proceedings of the $8^{\text {th }}$ International ISCRAM Conference - Lisbon, Portugal, May 2011. Available at: http://www.scribd.com/doc/59122167/A-Framework-forAnalyzing-Collective-Action-Events-on-Twitter (Accessed 01/03/2012)

Bennet, W. L. (2003) Communicating Global Activism. Strengths and Vulnerabilities of Networked Politics, Information, Communication \& Society, 6(2), pp. 143-168.

Bennet, W. L. \& Segerberg, A. (2011) Digital Media and the Personalization of Collective Action, Information, Communication \& Society, 14(6), pp. 770-799.

Bonacich, P. (1972) Factoring and weighting approaches to status scores and clique identification, Journal of Mathematical Sociology, 2, pp.113-120.

(1987) Power and Centrality: A Family of Measures, The American Journal

of Sociology, 92 (5), pp. 1170-1182.

Borgatti, S.P., Everett, M.G. \& Freeman, L.C. (2002) Ucinet 6 for Windows (Harvard: Analytic Technologies). 
Burt, R. S. (1987) Social Contagion and Innovation: Cohesion Versus Structural Equivalence, The American Journal of Sociology, 92(6), pp. 1287-1335.

Castells, M. (2001) The Internet Galaxy (Oxford: Oxford University Press). (2011) Communication Power (Oxford: Oxford University Press).

Christensen, C. (2011) Twitter Revolutions? Addressing Social Media and Dissent, The Communication Review, 14, pp. 155-157.

Cottle, S., Lester, L. (2011) Transnational Protests and the Media (New York: Peter Lang).

Cross, R., Borgatti, S. P., Parker, A. (2001) Beyond answers: dimensions of the advice network, Social Networks, 23, pp. 215-235.

della Porta, D. (2005) Multiple Belongings, Tolerant Identities, and the Construction of "Another Politics": Between the European Social Forum and the Local Social Fora in: D. Della Porta and S. Tarrow (Eds.) Transnational Protest and Global Activism, pp. 175-202 (Oxford: Rowman \& Littlefield).

della Porta, D. (2006) Globalization from below: transnational activists and protest networks (Minneapolis: University of Minnesota Press).

della Porta, D., Kriesi, H. \& Rucht, D. (2009) Social Movements in a Globalizing World (2nd edition) (New York, Palgrave Macmillan).

della Porta, D. \& Mosca, L. (2005) Global Net for Global Movements? A Network of Networks for a Movement of Movements, Journal of Public Policy, 25(1), pp. 165190.

della Porta, D. \& Tarrow, S. (2005) Transnational protest and Global Activism (New York: Rowman \& Littlefield Publishers).

Escobar, A. (2004) Other worlds are (already) possible. Self-organization, complexity, and post-capitalist cultures in: J. Sen, A. Anand, A. Escobar \& P. Waterman (Eds.) Challenging Empires, pp. 349-358 (New Delhi: the Viveka Foundation). 
Freeman, L.C. (1977) A Set of Measures of Centrality based on Betweenness, Sociometry, 40(1), pp. 35-41.

(1979) Centrality in social networks: Conceptual clarification, Social Networks, 1, pp. 215-239.

Garrido, M. \& Halavais, A. (2003) Mapping Networks of Support for the Zapatista Movement in: M. McCaughey \& M. D. Ayers (Eds.), Cyberactivism: Online Activism in theory and practice, pp. 165-184 (New York: Routledge).

Giugni, M. (2012) The Outcomes of the Occupy Movement: Which Lessons Can We Draw from the Social Movement Literature? Mobilizing Ideas. Available at: http://mobilizingideas.wordpress.com/2012/01/20/the-outcomes-of-the-occupymovement-which-lessons-can-we-draw-from-the-social-movement-literature/. (Accessed 01/03/2012).

Granovetter, M. (1976) Network sampling: some first steps, The American Journal of Sociology, 81(6), pp. 1287-1303.

Hadden, J. \& Tarrow, S. (2005) The Global Justice Movement in the United States since Seattle in della Porta (Ed.) The Global Justice Movement. Cross-National and Transnational Perspectives, pp. 210-231 (London: Paradigm).

Hanneman, R. A. \& Riddle, M. (2005) Introduction to social network methods (Riverside, CA: University of California, Riverside). Available at: http://www.faculty.ucr.edu/ hanneman/nettext/C18_Statistics.html\#ptwogrp (Accessed 01/03/2012).

Jackson, M. H. (1997) Assessing the structure of communication on the World Wide Web, Journal of Computer-Mediated Communication, 3(1). Available at: http://jcmc.indiana.edu/vol3/issue1/jackson.html (Accessed 01/03/2012). 
Keck, M. \& Sikkink, K. (1998) Activists Beyond Borders: Advocacy Networks and International Politics (Itacha, Cornell University Press)

Koopmans, R. (2004) Movements and Media: Selection Processes and Evolutionary Dynamics in the Public Sphere, Theory and Society, 33, pp. 367-391.

Langman, L. (2005) From Virtual Public Spheres to Global Justice: A Critical Theory of Internetworked Social Movements, Sociological Theory, 23(1), pp. 42-74.

Leite, J. C. (2005) The World Social Forum. Strategies of Resistance (Chicago: Haymarket Books).

McAdam, D. (1994) Culture and Social Movements in: E. Laraña, H. Johnston \& J. R. Gusfield (Eds.) New Social Movements; from ideology to identity, pp. 36-57 (Philadelphia, Temple University Press).

Mosca, L. \& della Porta, D. (2009) Unconventional Politics Online: Internet and the Global Justice Movement, in: D. Della Porta (Ed.) Democracy in Social Movements, pp. 194216 (New York: Palgrave Macmillan) .

Park, H. \& Thelwall, M. (2003) Hyperlink analyses of the World Wide Web: A review, Journal of Computer-Mediated Communication, 8(4). Available at http://jcmc.indiana.edu/vol8/issue4/park.html (Accessed 01/03/2012).

Procter, R., Vis F. \& Vox, A. (2011) Reading the Riots, Guardian. Available at: http://www.guardian.co.uk/uk/interactive/2011/dec/07/london-riots-twitter. (Accessed 01/03 2012).

Pudrovska, T. \& Ferree, M. M. (2004) Global Activism in Virtual Space: The European Women Lobby in the Network of Transnational Women's NGOs on the Web, Social Politics, 11(1), pp. 117-143.

Rahimi, B. (2011) The Agonistic Social Media: Cyberspace in the Formation of Dissent and Consolidation of State Power in Postelection Iran, The Communication Review, 14:3, 
pp.158-178.

Reiter, H., Andretta, M., della Porta, D. \& Mosca, L. (2007) The Global Justice Movement in Italy, in: D. della Porta (Ed.), The Global Justice movement, pp. 52-78 (London: Paradigm)

Routledge, P. \& Cumbers, A. (2009) Global justice networks: geographies of transnational solidarity (Manchester: Manchester University Press).

Schonleitner, G. (2003) World Social Forum: Making Another World Possible? in J. Clark (Ed.) Globalizing Civic Engagement, pp. 127-149 (London: Earthscan Publications).

Segerberg, A. \& Bennet W. L. (2011) Social Media and the Organization of Collective Action: Using Twitter to Explore the Ecologies of Two Climate Change Protests, The Communication Review 14(3): 197-215.

Smith, J. G., Smith, J. \& Johnston, H. (2002) Globalization and resistance: transnational dimensions of social movements (New York: Rowman \& Littlefield)

Stark, D., Vedres, B., \& Bruszt, L. (2005) Global Links, Local Roots? Varieties of Transnationalization and Forms of Civic Integration, ISERP Working Paper Series, Centre on Organizational Innovation, Columbia University.

Tarrow. S. (2005a) The New Transnational Activism (Cambridge: Cambridge University Press).

(2005b) The Dualities of Transnational Contention, Mobilization: An International Journal, 10(1), pp. 53-71.

(2011) Power in movement. Social Movement and Contentious Politics (3rd edition) (Cambridge: Cambridge University Press).

Tilly, C. (2004), Social Movements, 1768-2004 (London: Paradigm Publishers).

Van Aelst, P. \& Walgrave, S. (2004), New Media, new movements? The role of the internet in shaping the 'anti-globalization' movement in: Van de Donk et al. (Eds.) 
Cyberprotest. New media, citizens and social movements, pp. 97-122 (London: Routledge).

Wasserman, S. \& Faust, K. (1994) Social Network Analysis: Methods and Applications (Cambridge: Cambridge University Press).

Wood (2004) Breaking the Bank \& Taking to the Streets: How Protesters Target Neoliberalism, Journal of World-System Research, 10(1), pp. 69-90.

Tables and Figures

\begin{tabular}{ll}
\hline Africa & Social Forum \\
& Moroccan Social Forum \\
& Nigerian Social Forum \\
\hline South America & $\begin{array}{l}\text { Corrientes Social Forum } \\
\text { Brazilian Social Forum }\end{array}$ \\
\hline North America & Toronto Social Forum \\
& Boston Social Forum \\
\hline Asia & Kerala Social Forum \\
& Iranian Social Forum \\
\hline Europe & London Social Forum \\
& Greek Social Forum \\
\hline Oceania & Sydney Social Forum \\
& New Zealand Social Forum \\
\hline
\end{tabular}

Table 1: Initial Websites ${ }^{1}$

${ }^{1}$ Some of the original websites have in the meantime migrated to different platforms. However, the original web addresses were the following: Moroccan Social Forum: www.foraocialmaroc.org, Nigerian Social Forum: http://www.dawodu.com/nsf1.htm, Corrientes Social Forum: http://www.corrientesdepie.8k.com/foro3.htm, Brazilian Social Forum: http://www.fsb.org.br, Toronto Social Forum: www.torontosocialforum.ca, Boston Social Forum: www.bostonsocialforum.org, Kerala Social Forum : http://pd.cpim.org/2004/0104/01042004 c\%20p\%20aboo\%20backer.htm, Iranian Social Forum: www.iransocialforum.org, London Social Forum: http://www.londonsocialforum.org.uk, Greek Social Forum: www.socialforum-media.gr, Sydney Social Forum: www.sydneysocialforum.org, New Zealand Social Forum: http://www.socialforum.org.nz. 


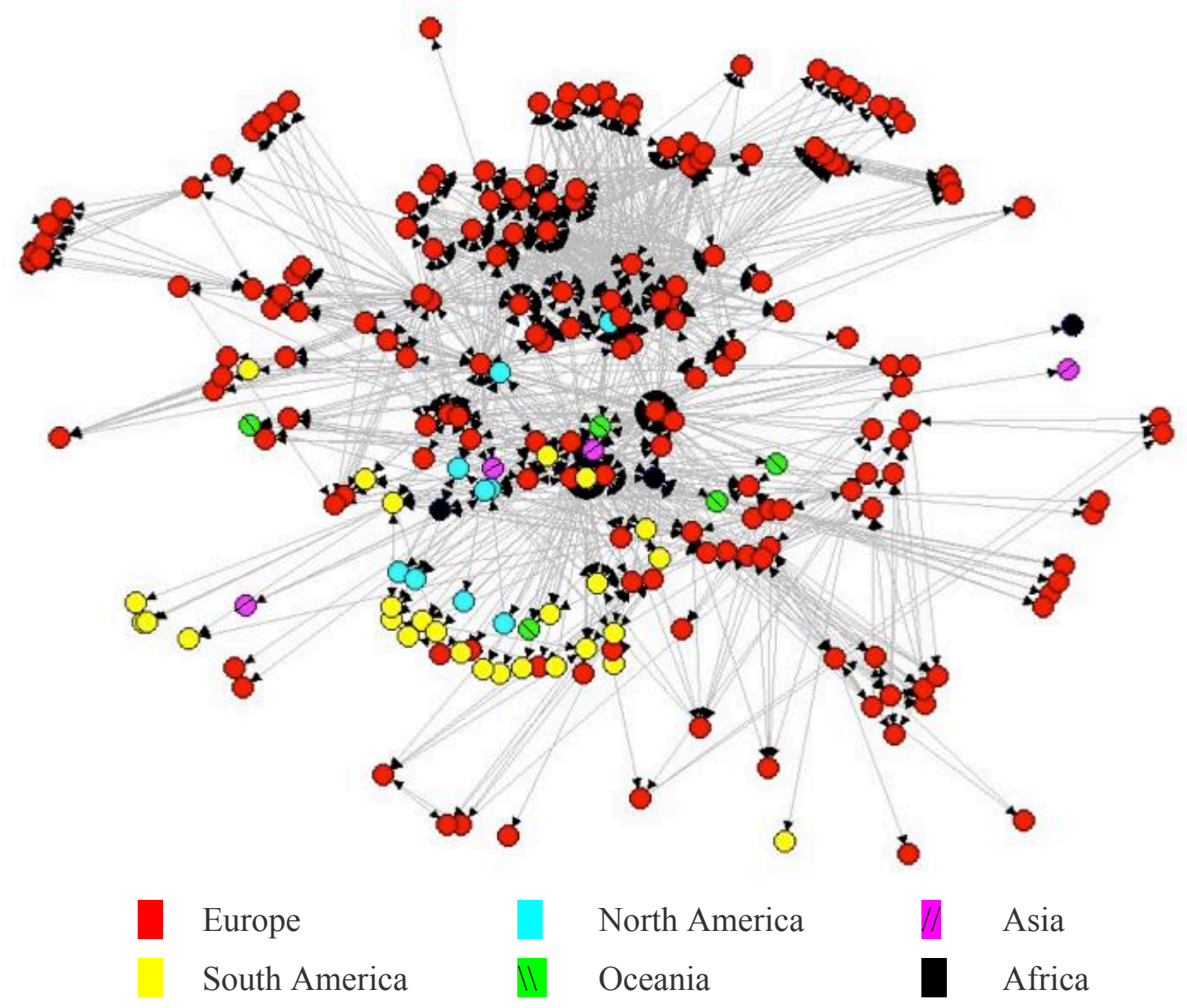

Figure 1: WSF Sample Online Network 


\begin{tabular}{lrrr}
\hline \multicolumn{1}{c}{ Forum } & Freeman (indegree) & Freeman (outdegree) & Betweenness \\
\hline Bergamo & 0.5 & $\underline{23.2}$ & 0.0 \\
Brindisi & 5.0 & $\underline{21.8}$ & 0.4 \\
Crescentino & 2.7 & $\underline{22.7}$ & 0.1 \\
Firenze & 5.0 & $\underline{22.7}$ & 0.4 \\
Legnago & 5.9 & $\underline{22.7}$ & 0.9 \\
Lodi & 4.0 & $\underline{23.2}$ & 2.7 \\
Modena & 5.5 & $\underline{21.4}$ & 0.4 \\
Novara & 6.0 & 13.2 & 0.4 \\
Torino & 10.0 & $\underline{21.4}$ & 2.4 \\
Austrian & 6.8 & $\underline{30.9}$ & $\underline{25.1}$ \\
European & $\underline{31.8}$ & 0.9 & 5.4 \\
New York & 4.1 & $\underline{24.6}$ & 9.6 \\
World-Brazil & $\underline{32.7}$ & 13.6 & $\underline{37.8}$ \\
World-India & $\underline{14.1}$ & 1.8 & 5.8 \\
\hline
\end{tabular}

Table 2: Centrality (normalised values, highest values underlined)

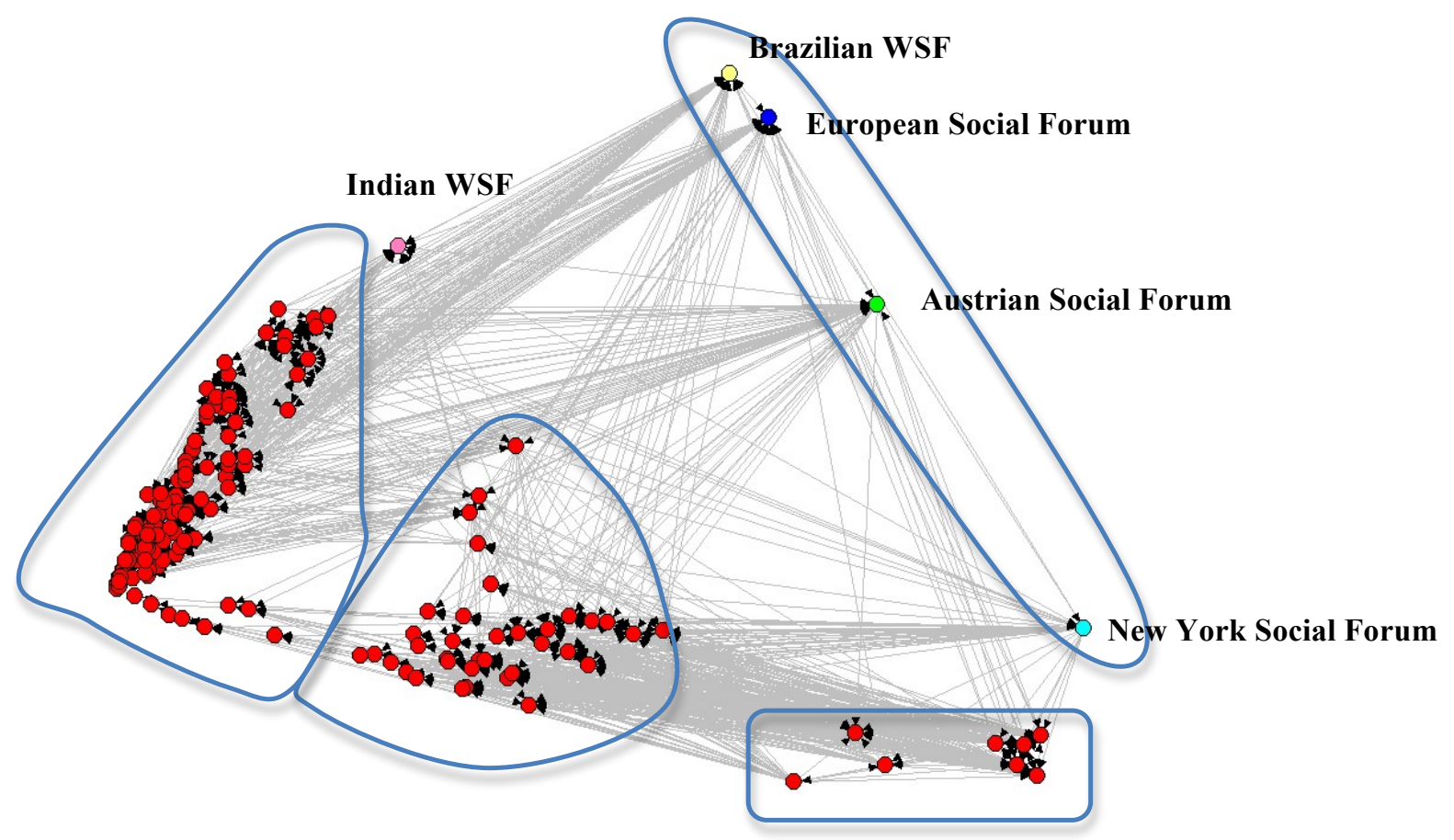

Figure 2: Principal Components Layout of WSF Online Network Sample 


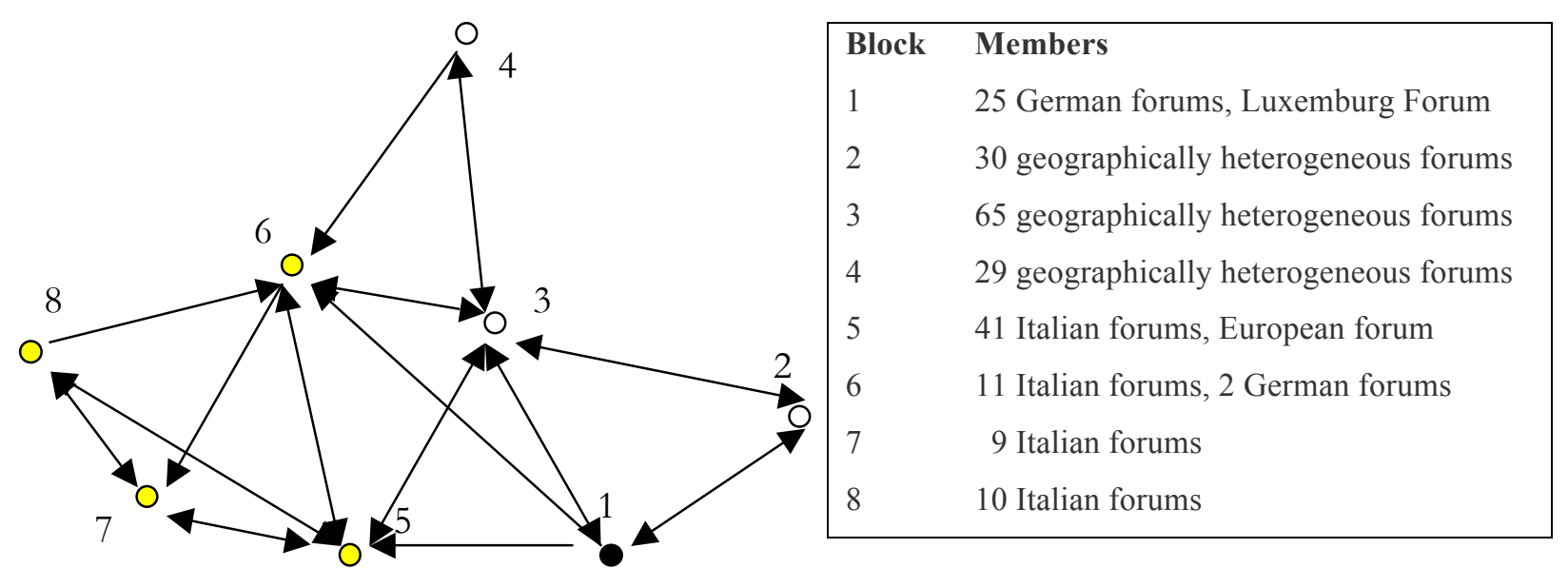

Figure 3: Table 3: Structural Equivalence Network and Blocks

\begin{tabular}{lcc}
\hline \multicolumn{1}{c}{ Independent } & St.dized Coefficient & Significance \\
\hline Intercept & 0.000000 & 1.000 \\
French & 0.073017 & 0.000 \\
English & 0.065218 & 0.000 \\
German & 0.101803 & 0.000 \\
Spanish & 0.041162 & 0.001 \\
Italian & 0.164136 & 0.000 \\
Portuguese & 0.034972 & 0.002 \\
Swedish & 0.076507 & 0.000 \\
Catalan & -0.000778 & 0.868 \\
Mix minor & 0.022565 & 0.008 \\
\hline
\end{tabular}

Table 4: Variable Homophily Test on Language

\begin{tabular}{lcc} 
Independent & St.dized Coefficient & Significance \\
\hline Intercept & 0.000000 & 1.000 \\
Oceania & 0.028140 & 0.002 \\
North America & 0.025452 & 0.006 \\
Asia & -0.001561 & 0.755 \\
South America & 0.033457 & 0.003 \\
Europe & 0.052195 & 0.000 \\
Africa & -0.001104 & 0.864 \\
\hline
\end{tabular}

Table 5: Variable Homophily Test on Geographical Location 


\begin{tabular}{lcc}
\hline Independent & St.dized Coefficient & Significance \\
\hline Intercept & 0.000000 & 1.000 \\
Oceania-Oceania & $\mathbf{0 . 0 3 0 1 5 6}$ & $\mathbf{0 . 0 0 7}$ \\
Oceania-North America & 0.012791 & 0.136 \\
Oceania-Asia & 0.000000 & 0.866 \\
Oceania-South America & 0.013660 & 0.245 \\
Oceania-Europe & 0.007273 & 0.720 \\
Oceania-Africa & 0.006964 & 0.261 \\
North America-Oceania & 0.004264 & 0.506 \\
North America-North America & $\mathbf{0 . 0 2 8 8 2 4}$ & $\mathbf{0 . 0 1 3}$ \\
North America-Asia & 0.004767 & 0.451 \\
North America-South America & $\mathbf{0 . 0 3 4 1 6 9}$ & $\mathbf{0 . 0 2 1}$ \\
North America-Europe & 0.054322 & 0.083 \\
North America-Africa & $\mathbf{0 . 0 1 6 5 1 6}$ & $\mathbf{0 . 0 3 9}$ \\
Asia-Oceania & 0.000000 & 0.865 \\
Asia-North America & 0.004767 & 0.422 \\
Asia-Asia & 0.000000 & 0.872 \\
Asia-South America & 0.022916 & 0.083 \\
Asia-Europe & 0.004073 & 0.762 \\
Asia-Africa & 0.000000 & 0.879 \\
South America-Oceania & 0.004553 & 0.699 \\
South America-North America & 0.008992 & 0.561 \\
South America-Asia & 0.010185 & 0.309 \\
South America-South America & $\mathbf{0 . 0 4 5 7 5 5}$ & $\mathbf{0 . 0 2 2}$ \\
South America-Europe & 0.006988 & 0.864 \\
South America-Africa & 0.002941 & 0.723 \\
Europe-Oceania & 0.010000 & 0.809 \\
Europe-North America & 0.009292 & 0.862 \\
Europe-Asia & 0.003055 & 0.864 \\
Europe-South America & 0.035309 & 0.829 \\
Europe-Europe & $\mathbf{0 . 1 0 0 6 2 9}$ & 0.377 \\
Europe-Africa & 0.014134 & 0.471 \\
Africa-Oceania & 0.000000 & 0.873 \\
Africa-North America & 0.000000 & 0.874 \\
Africa-Asia & 0.000000 & 0.883 \\
Africa-South America & 0.005882 & \\
Africa-Europe & & \\
\hline & & \\
\hline
\end{tabular}

Table 6: Structural Block Model Test: significant coefficients in bold font.

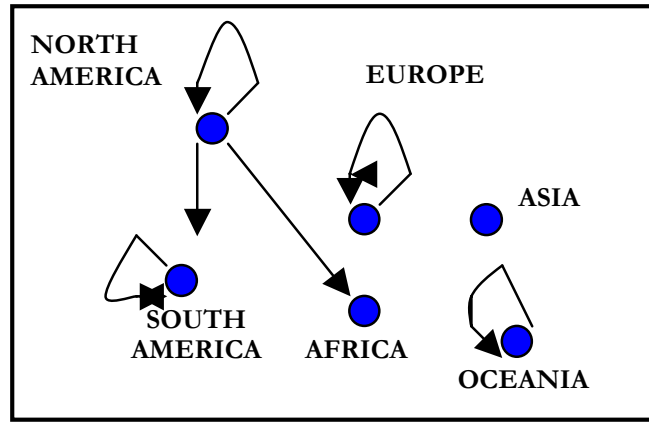

Figure 4: Patterns of Interaction among Continental Areas 


\section{Endnotes}

\footnotetext{
${ }^{\mathrm{i}}$ This was possible for South America, Asia, Europe and Oceania. As for North America and Africa the crosssearch has only respectively generated city forums and national forums.

ii The websites were downloaded in November 2005 using HTTrack Website Copier software, an offline browser. Websites different from social forums were excluded from the sample, because not directly representative of the WSF coalition. Hence, the 222-node sample network was designed by tracking all the hyperlinks from one social forum website to another until all outlinks were exhausted.

${ }^{\text {iii }}$ Relations among network nodes can be nondirectional or directional (Wasserman and Faust 1994: 44) with the former being considered as mutual, the latter as having a specific sender and a specific receiver.

${ }^{\text {iv }}$ Calling bjk the proportion of all geodesics connecting $\mathrm{j}$ to $\mathrm{k}$ through $\mathrm{i}$, i's betweenness is the sum of all bjk where $\mathrm{i}, \mathrm{j}$, and $\mathrm{k}$ are distinct (Freeman 1977: 36-37; 1979: 221-224).

${ }^{\mathrm{v}}$ The presence of incoming/outgoing links is based on the density of links between nodes in different blocks.

vi The test is based upon the densities within each block and is similar to performing an analysis of variance.

vii Languages used in more than two social forum websites.
} 